\title{
Spring-season climate variability in the central Ganadian Arctic Islands
}

\author{
T. A. Agnew and A. Silis \\ Atmospheric Environment Service, 4905 Dufferin Street, Downsview, Ontario M3H 5T4, Canada.
}

\begin{abstract}
The Resolute Bay area in the central Canadian Arctic Islands is in a region of maximum variability in $50 \mathrm{kPa}$ heights in spring. This is the northern part of an oscillation in large-scale atmospheric circulation called the Baffin Island-West Atlantic Oscillation (BWA). The historical record of temperature at Resolute Bay, Northwest Territories, over the 1948-93 period is compared with circulation patterns for extremely warm and cold spring seasons, using a composite technique and a simple index of the intensity of the BWA. The extremely cold spring of 1992, the second coldest of the 46 a record, was probably caused by reduced solar radiational forcing due to the increased dust veil caused by Mount Pinatubo.

Within each spring season, large-scale synoptic conditions provided an important control on the timing of critical stages leading to full snow melt on the sea-ice surface. The first stage is the change from dominance of the region by wintertime continental polar air to the frequent invasion of maritime polar air masses, resulting in increased cloud cover and reduced frequency of Arctic inversions. The second stage is the transition to full melt on the ice with a sharp drop in surface albedo. During the spring of 1993, the first stage was triggered by a major storm which moved through the area on 9-10 May 1993. The second snow-melt stage was triggered by a stationary upper ridge which remained over the area for a 2 week period from 15 May to early June and produced clear to scattered-cloud conditions and high downward solar radiation.
\end{abstract}

\section{INTRODUCTION}

The Sea-Ice Monitoring and Modelling (SIMMS) field experiment has been carried out on the sea ice off Resolute Bay $\left(74^{\circ} 45^{\prime} \mathrm{N}, 94^{\circ} 50^{\prime} \mathrm{W}\right)$ in the Canadian Arctic Islands every spring since 1990. An overview of the SIMMS project is presented by Barber and others (1992). The objective of this paper is to examine the variability in regional climate during the SIMMS experiments in comparison with the longer-term climate variability.

Long-term variability of Arctic climate has been the subject of increasing interest because of concern over Arctic climate warming due to the increased concentration of greenhouse gases (Roots, 1989). This concern stems from recent equilibrium general-circulation-model (GCM) results which suggest that global climate warming will be amplified in Arctic regions (IPCC, 1992). GCMs estimate large-scale seasonal changes in circulation patterns resulting from increased $\mathrm{CO}_{2}$ forcing. One of many reasons for their limited use at regional and local scales is their limited spatial resolution. The extent to which regional climate variability can be explained by large-scale circulation could lead to methods of extrapolating from GCMs to changes in regional and local climate. As a result an attempt is made to relate largescale circulation to spring-season climate in the area.

Changes in large-scale circulation control the movement of air masses and storm tracks and are therefore important in determining the timing of critical stages in the spring transition period during SIMMS. The first critical stage is an abrupt increase in cloudiness and surface temperatures and decreased frequency of Arctic inversions, associated with the advection of warm, moist maritime polar air into the region. The second stage is the onset of snow melt on the sea-ice surface. The timing of these stages and the changes in synoptic regime which occur are important for interpretation of results of individual SIMMS projects within each spring programme and from year to year.

To examine the long-term climate, the Resolute Bay weather-station temperature record was used. The Resolute Bay weather station is a principal observing station of the Atmospheric Environment Service with continuous weather records going back to 1948. The surface-temperature record was tested for inhomogeneity and corrected where necessary using methods described by Gullett and others (1991). Mean daily temperatures were averaged to produce spring-season values for April, May and June, corresponding to the period of the SIMMS field experiments. Seasonal values were then subtracted from normals for the 1951-80 period to produce temperature anomalies. The large-scale circulation was examined using daily gridded $50 \mathrm{kPa}$ (500 mbar) data derived from $00 \mathrm{Z}$ observations. These data consisted of 455 latitude-longitude grid points over the Northern Hemisphere from the North Pole to about $30^{\circ} \mathrm{N}$ latitude. Average monthly and seasonal $50 \mathrm{kPa}$ gridded data were calculated. 


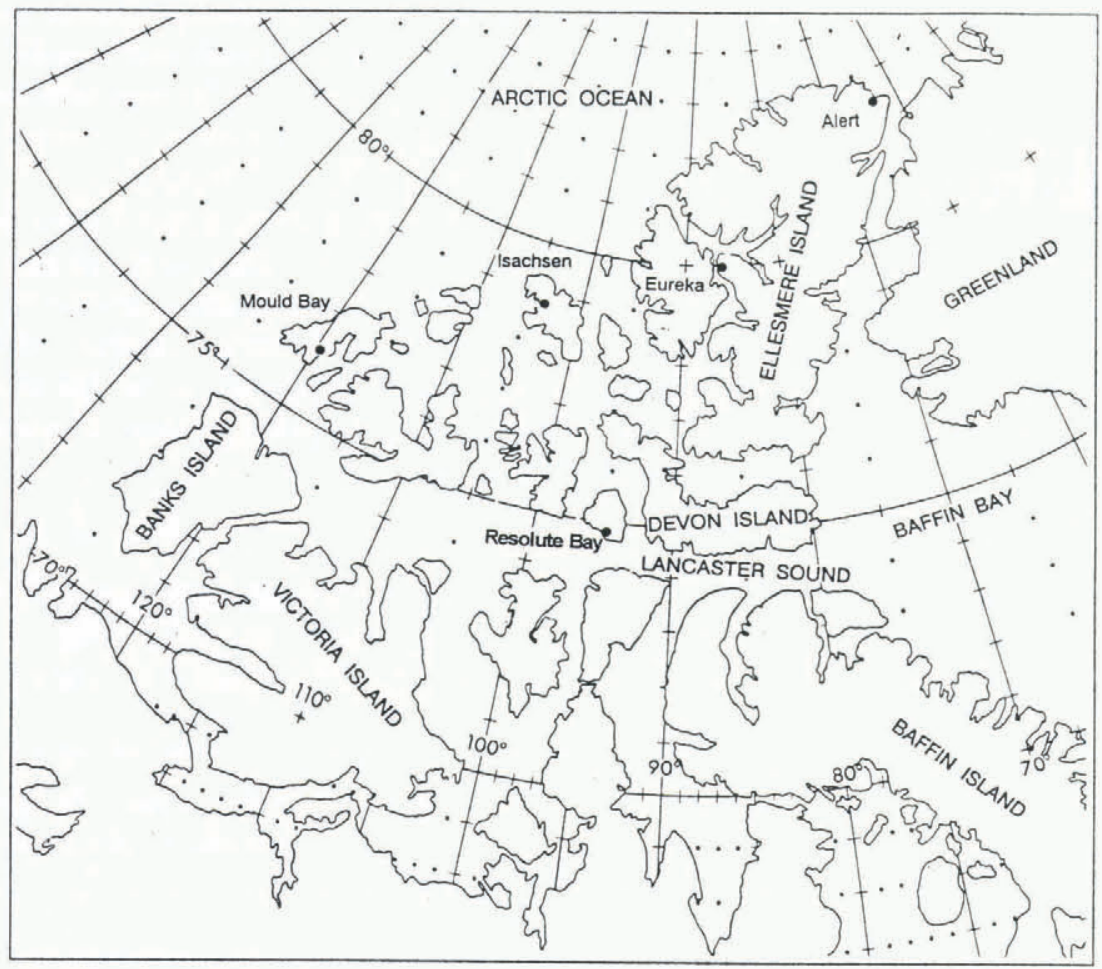

Fig. 1. Location map of the Canadian Arctic Islands. The SIMMS experiments take place about $10 \mathrm{~km}$ south of Resolute Bay on the sea ice facing into Lancaster Sound.

\section{GLIMATE CONTROLS OVER THE REGION}

The SIMMS field programme takes place in the approximate geographic centre of the Canadian Arctic Islands, off the south coast of Cornwallis Island facing Lancaster Sound (Fig. 1). The general climate of the area is described by Maxwell (1981) who identifies cyclone/ anticyclone activity, large-scale physiography, net radiation, and the sea-ice water regime as the main climate controls for the area.

The cyclone frequency is considerably less than in the regions to the east towards Baffin Bay and to the west towards the Arctic Ocean and Beaufort Sea. The Baffin Bay region is influenced by a high frequency of cyclones tracking up from the main storm track which crosses North America (Klein, 1957; Zishka and Smith, 1980). These cyclones tend to occlude in the Baffin Bay area but do not move into the central Arctic Islands due to the barrier provided by the mountainous terrain of Ellesmere, Devon and Baffin Islands. The region to the west towards the Arctic Ocean has a contrasting anticyclone/cyclone regime in winter and summer (Serreze and Barry, 1988). In winter, this region is influenced by semi-permanent high pressure over the Beaufort Sea producing a high frequency of anticyclonic activity. In summer, the region is influenced more by storms which move into the Beaufort Sea area from the west, southwest and north.

Figures 2 and 3 show the $50 \mathrm{kPa}(500 \mathrm{mbar})$ circulation over the Northern Hemisphere and the variability in $50 \mathrm{kPa}$ height in spring. The Canadian Arctic Islands are situated under the deepest part of the circumpolar vortex and in a region of large $50 \mathrm{kPa}$ height variability. The seasonal variability is calculated from the daily $00 Z$ heights over the 1951-80 period at each grid point. This variability usually occurs over $1-2$ week time-scales, longer than typical cyclone/anticyclone activity. Studies by Knox and Hay (1985) suggest that this variability is due to a high frequency of blocking activity in the region. The maximum variability, southeast of Resolute Bay over Baffin Island, is comparable in magnitude to variability

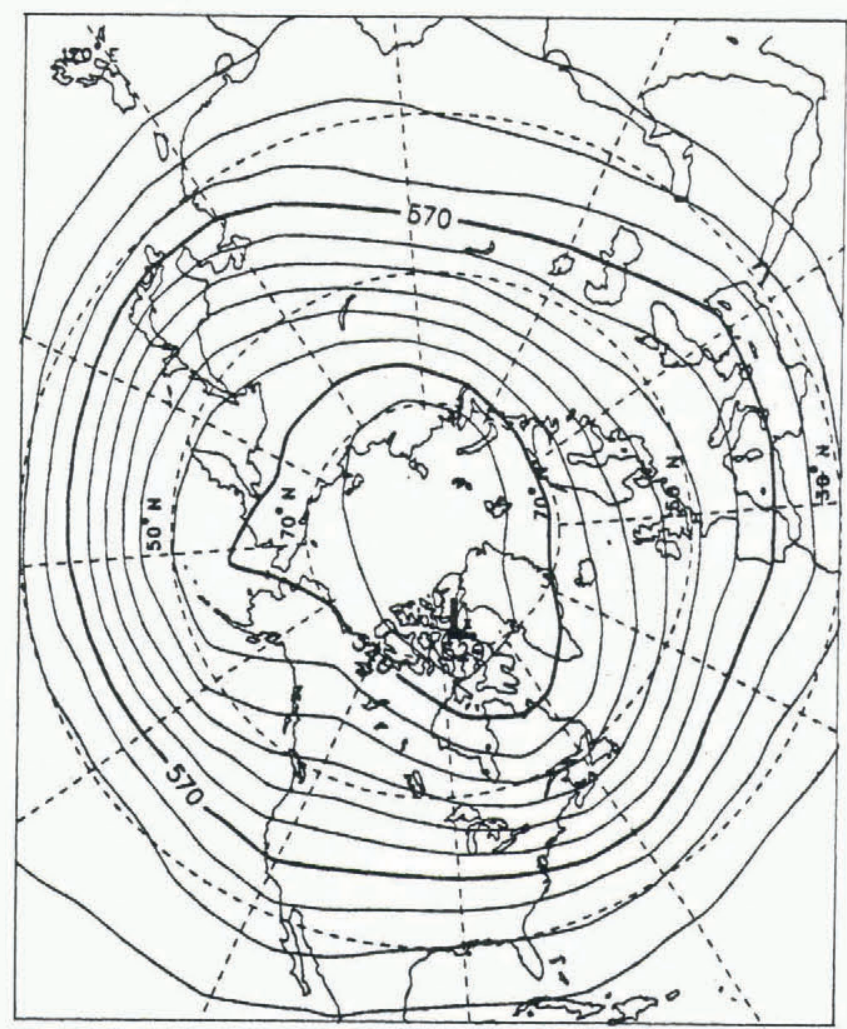

Fig. 2. The 1951-80 mean 50 kPa heights over the Northern Hemisphere. 
over the North Pacific and North Atlantic. This maximum in $50 \mathrm{kPa}$ variability suggests that large-scale circulation plays a greater than normal role in regional changes in weather for the area.

The influence of large-scale circulation on regional climate has been studied extensively over the last decade. Perhaps the best-known northern study of large-scale circulation and weather is the "seesaw" in temperature between the west coast of Greenland and northern Europe caused by an oscillation in surface pressure over a broad region of the North Atlantic (Rogers and van Loon, 1979). This oscillation is referred to as the North Atlantic Oscillation (NAO) and an index of its intensity is usually defined as the difference between the normalized winter surface-pressure anomaly for Ponta Delgada (Azores) and that for Akureyri (Iceland). It has been used in several climate studies relating circulation to regional climate (Lamb and Peppler, 1987; Moses and others, 1987). The NAO index defines a dipole-like mode of variability in the North Atlantic between the Icelandic low and the Atlantic sub-tropical high.

Studies of the principal modes of low-frequency interannual variability of the atmosphere have identified the NAO as a particularly strong mode present throughout the year Barnston and Livezey, 1987). The NAO is usually separated into a West Atlantic (WA) and East Atlantic Oscillation (EA). Neither the NAO nor the WA captures the high variability in $50 \mathrm{kPa}$ height over the Baffin Island area (Fig. 3). As a result a separate oscillation, the Baffin Island/West Atlantic Oscillation (BWA), is defined by Knox and Hay (1985), associated with $50 \mathrm{kPa}$ variability over this area. Justification for this is based on Knox's detailed examination of the Namias Teleconnection Atlas No. 29 (Namias, 1982; personal communication from J. Knox, 1993). The NAO, WA and

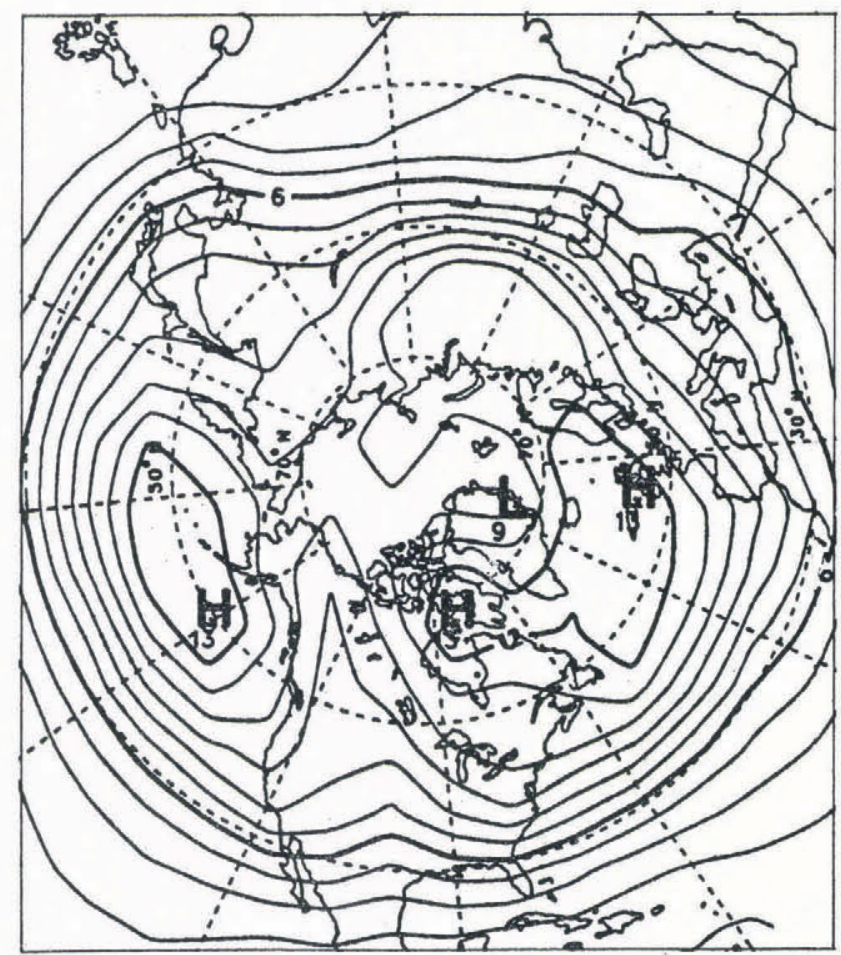

Fig. 3. The slandard deviation of $50 \mathrm{kPa}$ heights for the 1951-80 period.
BWA can all be thought of as manifestations of the "North Atlantic Oscillation mode" but with distinct differences in phase. The separation into different indices is not meant to suggest an intrinsic dynamic difference between NAO, WA and BWA.

From the mean monthly $50 \mathrm{kPa}$ fields, BWA, WA and NAO indices for spring were calculated from the monthly grid values using formulae shown in Table 1. Each index represents a difference in geopotential height between the two centres expressed in decametres and represents the strength of the poleward height gradient between the two centres.

Table 1. Teleconnection indices derived for spring from the $50 \mathrm{kPa}$ gridded data. Z(lat., long.) is the height anomaly using the 1947 87 period as normal

Name Index formula for spring (using $50 \mathrm{kPa}$ geopotential heights (Z) at indicated grid points)

North

Atlantic

Oscillation $0.5\left\{\mathrm{Z}\left(65^{\circ} \mathrm{N}, 30^{\circ} \mathrm{W}\right)-\mathrm{Z}\left(35^{\circ} \mathrm{N}, 30^{\circ} \mathrm{W}\right)\right\}$

NAO

Baffin

Island-West

Atlantic

Oscillation

(BWA)

West

Atlantic

Oscillation

$0.5\left\{\mathrm{Z}\left(55^{\circ} \mathrm{N}, 50^{\circ} \mathrm{W}\right)-\mathrm{Z}\left(35^{\circ} \mathrm{N}, 40^{\circ} \mathrm{W}\right)\right\}$

(WA)

\section{SPRING TEMPERATURE VARIABILITY SINCE 1948}

Figure 4 shows a plot of spring temperature departures for the 1948-93 period and the 5 year running mean applied to remove the high-frequency inter-annual variability and show longer-term trends. Table 2 lists the spring temperature anomalies and normalized anomalies (i.e. divided by the rms variability so that the anomaly is scaled like a t-variable). A t-value of about 1.65 represents a statistically significant deviation from climatology at the $95 \%$ level.

The 5 a running mean shows warm temperatures at the start of the record which probably marks the end of the general warming over the Arctic that occurred in the 1920s, 1930 s and 1940s (Kelly and others, 1982). Temperatures were near normal in the late 1950s and early 1960s. The early 1970s were particularly cold. The long-term trend then reverts to near normal during the 1970 s and early 1980 s, becoming slightly positive in the late 1980 s. There is no significant overall trend in the record.

The first two spring years of the SIMMS field programme (1990 and 1991) were warmer than normal but not exceptional. The spring of 1993 was the warmest 


\section{Resolute Bay, NWT}

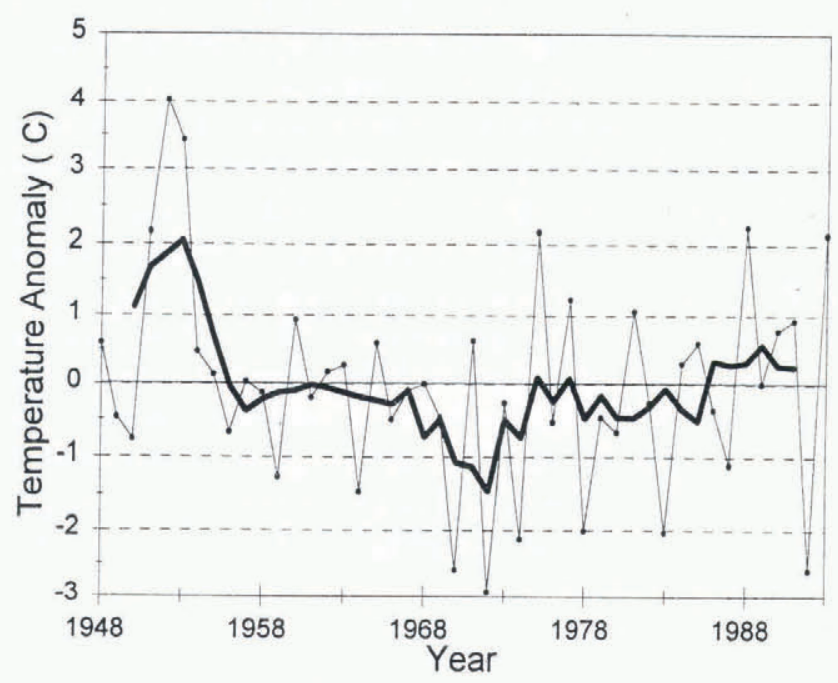

Fig. 4. Spring surface temperature anomalies for the 1948 93 period based on the Resolute Bay weather-station record.

during the field programme and the sixth warmest of the entire record. The spring of 1992 was the second coldest of the 46 year record, exceeded only by the extremely cold spring of 1972. The five coldest springs in order of severity were 1972, 1992, 1970, 1974 and 1983. The five warmest springs were 1952, 1953, 1988, 1951 and 1975.

The abruptly colder 1992 spring season merits further comment. This very cold spring occurred over a large part of the eastern Canadian Arctic Kerr, 1993), approximately 10 months after the eruption of Mount Pinatubo. GCM modelling studies by Hansen and others (1992) suggest that Mount Pinatubo injected sufficient sulphur-rich material into the stratosphere to reduce solar radiation and cool mean global surface temperatures by as much as $0.5^{\circ} \mathrm{C}$ for a $1-2$ year period. A delay of several months in the cooling signal was expected to allow the dust veil to spread over the hemisphere and overcome the inertia of the climate system. A delay in the Arctic until the spring would also be expected since it is only with the return of $24 \mathrm{~h}$ sunshine that reduced solar-radiation forcing due to increased stratospheric aerosols would occur. In the model simulation, Pinatubo reduced temperatures by 3 standard deviations of the annual global mean temperature.

\section{TEMPERATURE ANOMALIES AND LARGE-} SGALE CIRGULATION

To examine the changes in $50 \mathrm{kPa}$ circulation patterns which occur for extremes in spring temperatures, a composite of the circulation for the five warmest and the five coldest springs was made. The difference between the warm and cold composites is shown in Figure 5. The pattern shows abovenormal height over the Canadian Arctic Islands, as expected, since surface temperatures should be reflected through the lower troposphere. Also present is a north south dipole pattern between the Canadian Arctic Islands and the
Table 2. Spring-season lemperature anomalies. Asterisks indicate anomalies that are significant at the $95 \%$ level

Tear Temperalure anomaly t-statistic for temperature

${ }^{\circ} \mathrm{C}$

\begin{tabular}{|c|c|c|}
\hline 1948 & 0.60 & 0.41 \\
\hline 1949 & -0.46 & -0.32 \\
\hline 1950 & -0.76 & -0.52 \\
\hline 1951 & 2.17 & 1.48 \\
\hline 1952 & 4.04 & $2.75^{*}$ \\
\hline 1953 & 3.44 & 2.34 * \\
\hline 1954 & 0.47 & 0.32 \\
\hline 1955 & 0.14 & 0.09 \\
\hline 956 & -0.66 & -0.45 \\
\hline 1957 & 0.04 & 0.02 \\
\hline 958 & -0.13 & -0.09 \\
\hline 1959 & -1.26 & -0.86 \\
\hline 1960 & 0.94 & 0.64 \\
\hline 961 & -0.20 & -0.13 \\
\hline 1962 & 0.17 & 0.12 \\
\hline 963 & 0.27 & 0.18 \\
\hline 1964 & -1.46 & -1.00 \\
\hline 1965 & 0.60 & 0.41 \\
\hline 1966 & -0.50 & -0.34 \\
\hline 1967 & -0.10 & 0.07 \\
\hline 1968 & 0.00 & 0.00 \\
\hline 969 & -0.46 & -0.32 \\
\hline 1970 & -2.60 & $-1.77^{*}$ \\
\hline 971 & 0.64 & 0.43 \\
\hline 972 & -2.93 & $-1.99^{\prime \prime}$ \\
\hline 973 & -0.26 & -0.18 \\
\hline 974 & -2.13 & -1.45 \\
\hline 975 & 2.17 & 1.48 \\
\hline 976 & -0.53 & -0.36 \\
\hline 977 & 1.24 & 0.84 \\
\hline 978 & -2.00 & -1.36 \\
\hline 979 & -0.46 & -0.32 \\
\hline 980 & 0.66 & -0.45 \\
\hline 981 & 1.07 & 0.73 \\
\hline 982 & -0.26 & -0.18 \\
\hline 983 & -2.03 & -1.38 \\
\hline 984 & 0.30 & 0.21 \\
\hline 985 & 0.60 & 0.41 \\
\hline 986 & 0.36 & -0.25 \\
\hline 987 & -1.10 & -0.75 \\
\hline 988 & 2.24 & 1.52 \\
\hline 89 & 0.00 & 0.00 \\
\hline 990 & 0.79 & 0.54 \\
\hline 9 & 0.94 & 0.64 \\
\hline & -2.60 & $-1.77^{*}$ \\
\hline 99 & 2.14 & 1.45 \\
\hline
\end{tabular}

western Atlantic, similar to the Baffin Island-West Atlantic Oscillation. Lower heights centred over the Norwegian Sea in Figure 5 reflect the seesaw in temperatures with northern Europe discussed earlier. The overall pattern is very similar to Barnston and Livezey's (1987; figure 2 for May and June 


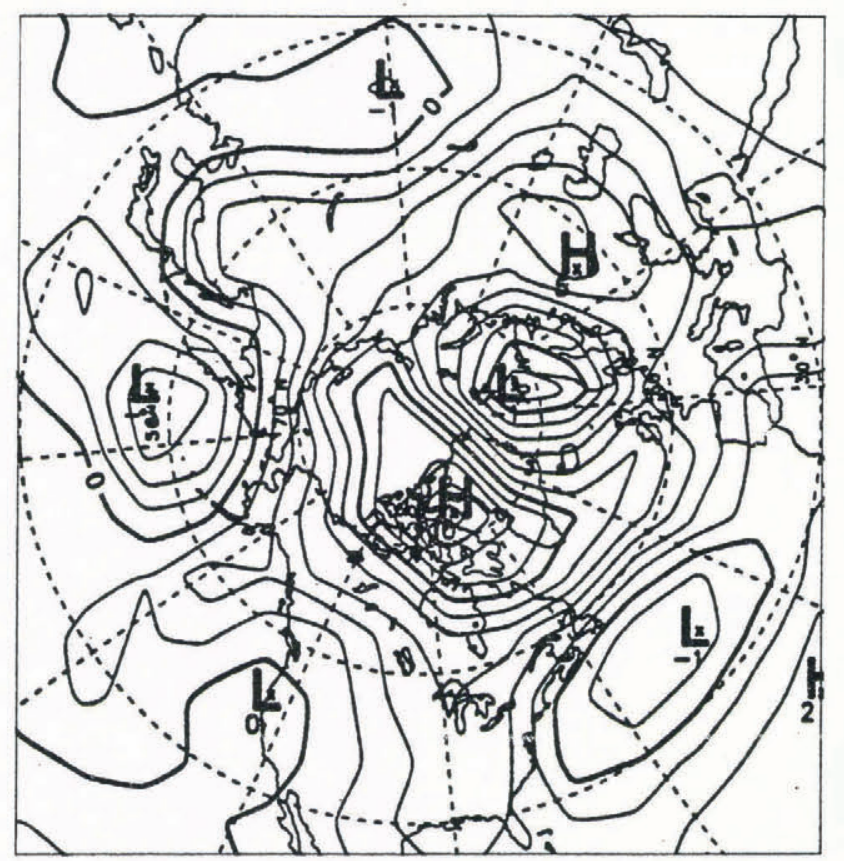

Fig. 5. $50 \mathrm{kPa}$ difference pattern between the five warmesl and five coldest spring seasons at Resolute Bay.

and suggests increased meridional circulation over northern Canada, with reduced westerlies over eastern North America, displaced southward over the North Atlantic.

As a further comparison with circulation, the time series of temperature anomalies were compared with the BWA, WA, and NAO indices. Only the BWA index was significantly correlated with the temperature anomaly (Fig. 6). The correlations were 0.56 for the BWA index, 0.4 for the NAO index, and 0.24 for the WA index.

\section{Temperature Anomaly vs. BWA Index}

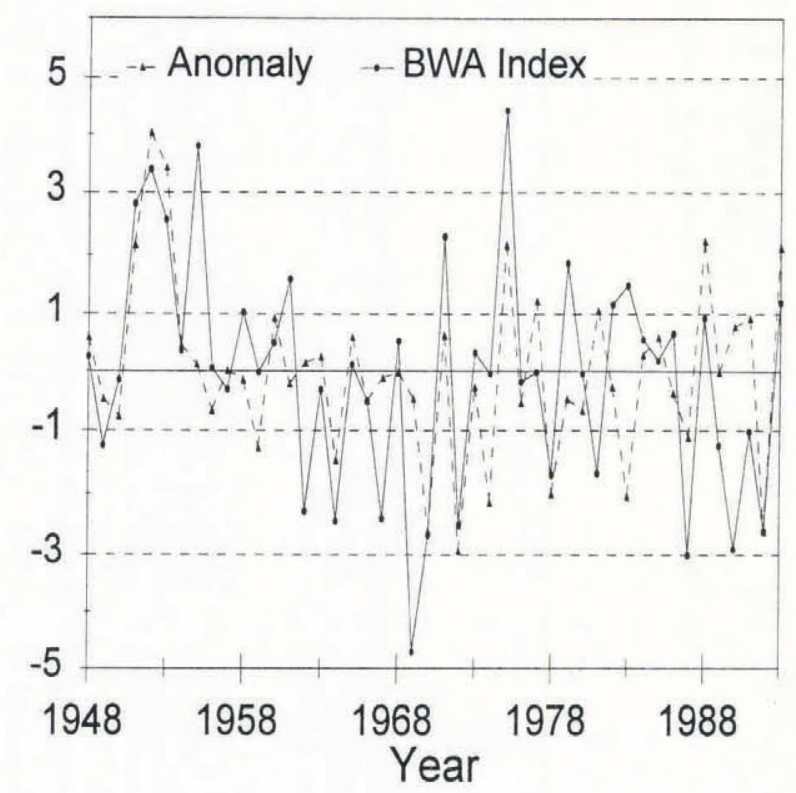

Fig. 6. Plot of the BWA index in geopotential decametres against temperature anomaly in ${ }^{\circ} \mathrm{C}$.

\section{CRITICAL EVENTS DURING SIMMS 1993}

As indicated, the 1993 spring season was the sixth warmest spring in the 46 year record at Resolute Bay. In 1993, the transition from predominantly continental polar air to more frequent invasions of warmer maritime polar air occurred with a major storm which moved into the Canadian Arctic Islands from the Keewatin/western Hudson Bay region on 9 -10 May (Fig. 7). Figure 8 shows a sharp increase in surface air temperature and snow temperature following Julian day 130 (10 May) which persisted for the rest of the SIMMS experiment after the storm passed. Similar increases in relative humidity are observed. After the warming, air temperature in Figure 8 mostly exceeds snow temperature, implying downward sensible-heat flux and warming of the surface by the warm, moist air.

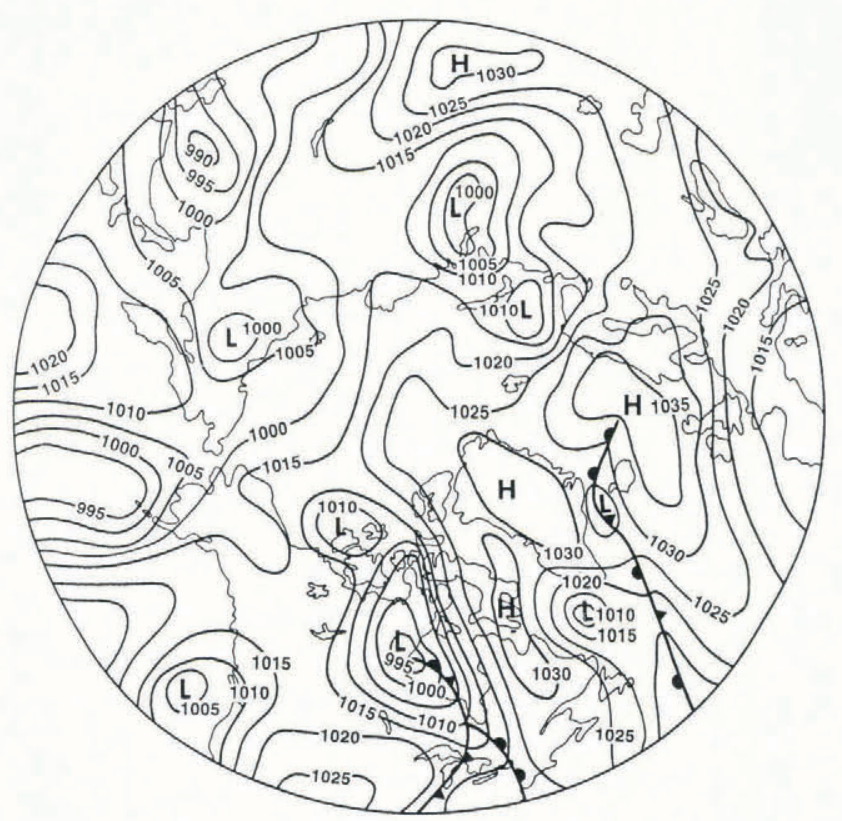

Fig. 7. Surface pressure analysis showing a major storm which moved through the Canadian Northwest Territories into the Arctic Islands at 1200 GMT on 10 May 1993.

The second stage is the onset of snow melt on the seaice surface. In 1993, the precursor to melt was a $50 \mathrm{kPa}$ ridge which moved into the southern Greenland-Baffin Bay area around 21 May, extending across the Arctic Islands into an intense high over the western Arctic basin. At the surface, high pressure dominated over the region for more than 2 weeks. Figure 9 shows the surface analysis on 27 May at 1200 GMT, with an intense 1035 mbar high over the region. This situation persisted with only minor changes until early June, producing a long period of clear to scattered-cloud days giving high values of average incident solar radiation $(K d)$. Figure 10 shows absorbed solar radiation, i.e. incident solar radiation $(K d)$ minus reflected solar $(K u)$, at the multi-year sea-ice site. The gradual increase in absorbed solar radiation is apparent. Of particular note is the sharp increase between Julian days 147 and 155 (27 May 4 June) when this stationary high was most intense. This eventually leads to a rapid 


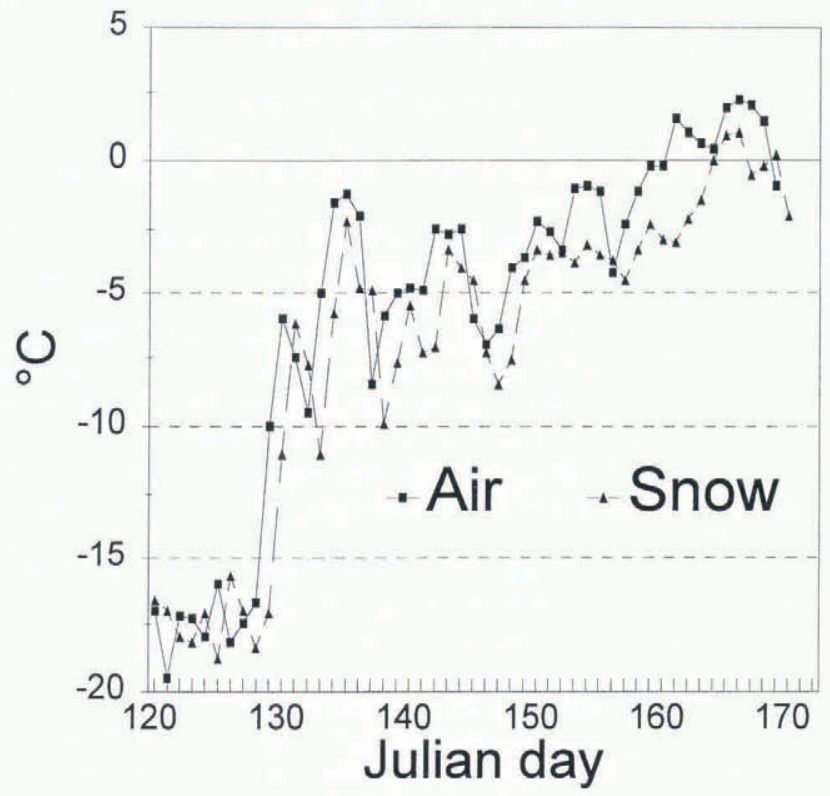

Fig. 8. Time series of daily average air and snow temperatures during SIMMS'93 at the first-year ice sile.

drop in $K u$ and surface albedo as the snow surface begins to melt.

This warming situation was exceptional as indicated by comparison with the long period of weather records at the Resolute Bay weather station. Weekly temperature values compared to the 1951-80 normal period were over $2^{\circ}$ above normal from mid-May until the end of the field programme (not shown). Other parameters for the spring months such as the percentage of normal bright sunshine were also above normal for May and June. These warm conditions were not local but extended over the central and western Canadian Arctic Islands and into western Canada.

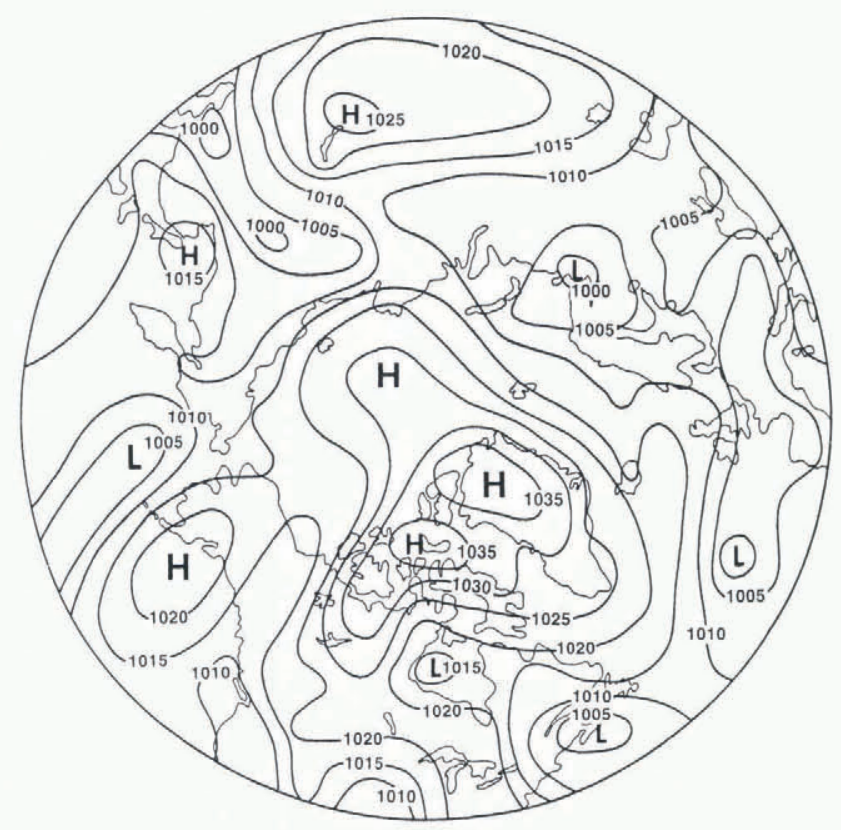

Fig. 9. Surface pressure analysis for 1200 GMT on 27 May 1993 showing an intense 1035 mbar high pressure over the Arctic Islands.

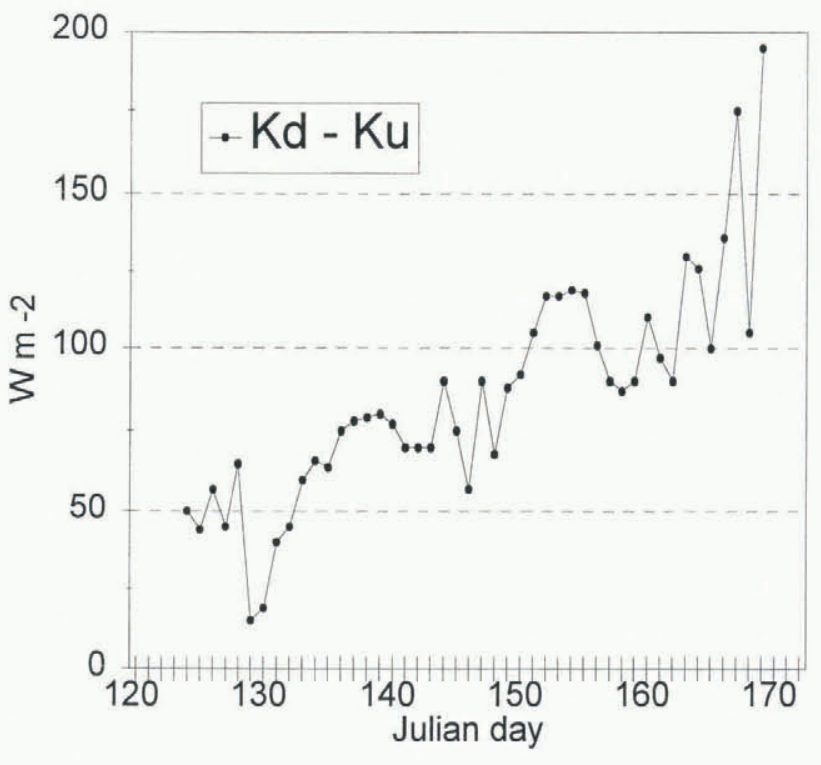

Fig. 10. Time series of daily absorbed solar radiation, i.e. incident solar radiation ( $K d$ ) minus reflected solar radiation $(K u)$, at the multi-year sile.

\section{CONGLUSIONS}

The SIMMS study area is in a region of the Arctic where there is maximum large-scale circulation variability in spring. Examination of variability of spring temperatures in the Resolute Bay area in the central Canadian Arctic Islands indicates that the five coldest springs in order of severity were 1972, 1992, 1970, 1974 and 1983. The five warmest springs in descending order were 1952, 1953, 1988, 1951 and 1975. The extremely cold spring of 1992, the second coldest recorded, was probably caused by reduced solar radiational forcing due to the increased dust veil caused by Mount Pinatubo 10 months earlier. The inertia of the climate system, the delay in spreading the dust veil over the Northern Hemisphere and the timing of the arrival of continuous daylight in the spring suggest that this delay is reasonable.

Extremes in temperature occurred in conjunction with a change in circulation pattern referred to as the Baffin Island West Atlantic Oscillation (BWA). A BWA index describing this oscillation was significantly correlated with the temperature anomaly. Correlations with the WA and NAO oscillations were not significant.

The spring-season weather and climate of the area are strongly influenced by changes in large-scale atmospheric circulation which controls the movement of air masses and storm tracks and thus the timing of two important stages during this period. The first is the transition from predominantly continental polar air over the region to the frequent invasion of warm, moist maritime polar air. This transition brings a sharp increase in cloudiness, surface temperature and relative humidity, reduced frequency of Arctic inversions and increased frequency of positive net radiation. The second stage is the onset of snow melt on the sea-ice surface and is accompanied by an abrupt change in surface albedo and increases in solar radiation absorption and positive net radiation.

During the spring of 1993 , the start of the first stage was triggered by a major storm which moved through the area on 9-10 May 1993. The snow-melt stage was 
triggered by a stationary upper ridge which remained over the area for a 2 week period from 15 May to early June and produced clear/scattered-cloud conditions and high incident solar radiation which accelerated snow melt on the sea-ice surface.

\section{ACKNOWLEDGEMENTS}

The SIMMS programme has been initiated by the Earth Observations Laboratory of the Institute for Space and Terrestrial Science at the University of Waterloo. The authors would like to thank Dr J. Knox for helpful discussions concerning the Baffin Island-West Atlantic Oscillation; Mr L. Welsh for supplying data on the atmospheric-circulation indices; and Dr M. Serreze for his helpful comments on an earlier draft. The authors would also like to acknowledge financial support for this study from the Office of Energy Research and Development of the Canadian Government.

\section{REFERENGES}

Barber, D., D. G. Flett, R. A. De Abreu and E. F. Le Drew, 1992. Spatial and temporal variations of sea ice geophysical properties and microwave remote sensing observations. The SIMMS'90 experiment. Artic, 45(3), 233251.

Barnston, A. G. and R. E. Livezey. 1987. Classification, seasonality and persistence of low-frequency atmospheric circulation patterns. Mon. Weather Rev., 115, 1083-1126.

Gullett, D. W., L. Vincent and L. H. Malone. 1991. Homogeneity testing of monthly lemperature series: application of multiple-phase regression models with mathematical changepoints. Downsview, Ontario, Environment Canada. Atmospheric Environment Service. Canadian Climate Centre Report 91-10.
Hansen, J., A. Lacis, R. Reudy and M. Sato. 1992. Potential climate impacts of Mount Pinatubo eruption. Geophys. Res. Lett., 19 (2), 215218.

Intergovernmental Panel on Climate Change (IPCC). 1992. The IPCC 1990 and 1992 assessments. Geneva, World Meteorological Organisation. United Nations Environment Programme. Intergovernmental Panel on Climate Change.

Kelly, P. M., P. D. Jones, C. B. Sear, B. S. G. Cherry and R. K. Tavakol. 1982. Variations in surface air temperatures: Part 2. Arctic regions, 1881-1980. Mon. Weather Rev., 110 2), 71-83.

Kerr, R. A. 1993. Pinatubo global cooling on target. Science, 259, 594.

Klein, W. H. 1957. Principal tracks and mean frequencies of cyclones and antigclones in the Northern Hemisphere. Washington, DC, U.S. Weather Bureau. National Weather Service. Research Paper 40.

Knox, J. L. and J.E. Hay. 1985. Blocking signatures in the Northern Hemisphere: frequency, distribution and interpretation. F. Climatol., 5, 1-16.

Lamb, P.J. and R. A. Peppler, 1987. North Atlantic oscillation: concept and an application. Bull. Am. Meteorol. Soc., 68 10), 1218-1225.

Maxwell, J. B. 1981. Climatic regions of the Canadian Arctic Islands. Arctic, 34(3), 225-240.

Moses, T., G. N. Kiladis, H.F. Diaz and R. G. Barry. 1987. Characteristics and frequency reversals in mean sea level pressure in the North Atlantic sector and their relationship to long-term temperature trends. 7. Climatol., 7, 13-30.

Namias, J. 1982. The new Scripps atlas of $700 \mathrm{mb}$ height teleconnections some novel findings. In Proceedings, 6th Anmual Climale Diagnostics Workshop, 14 16 October 1981. Washington, D.C., National Oceanographic and Atmospheric Administration, U.S. Department of Commerce, 95-104.

Rogers, J.S. and H. van Loon. 1979. The seesaw in winter temperatures between Greenland and northern Europe. Part II: Some oceanic and atmospheric effects in middle and high latitudes. Mon. Weather Rev., 107, 509-519.

Roots, E. F. 1989. Climate change: high-latitude regions. Climatic Change, $15\left(\begin{array}{llll}1 & 2), 223-253 .\end{array}\right.$

Serreze, M. C. and R.G. Barry. 1988. Synoptic activity in the Arctic basin, 1979 85. Journal of Climale, 1 12), 1276-1295.

Zishka, K. M. and P.J. Smith. 1980. The climatology of cyclones and anticyclones over North America and surrounding ocean environs for January and July, 1950-70. Mon. Weather Rev., 108(4), 387401. 